University of Nebraska - Lincoln

DigitalCommons@University of Nebraska - Lincoln

Faculty Publications - Chemistry Department Published Research - Department of Chemistry

$10-2010$

\title{
Nanopod Formation through Gold Nanoparticle Templated and Catalyzed Cross-linking of Polymers Bearing Pendant Propargyl Ethers
}

\author{
Ke Zhang \\ Northwestern University \\ Joshua I. Cutler \\ Northwestern University \\ Jian Zhang \\ University of Nebraska-Lincoln, jzhang3@unl.edu \\ Dan Zheng \\ Northwestern University \\ Evelyn Auyeung \\ Northwestern University \\ See next page for additional authors
}

Follow this and additional works at: https://digitalcommons.unl.edu/chemfacpub

Part of the Chemistry Commons

Zhang, Ke; Cutler, Joshua I.; Zhang, Jian; Zheng, Dan; Auyeung, Evelyn; and Mirkin, Chad A., "Nanopod Formation through Gold Nanoparticle Templated and Catalyzed Cross-linking of Polymers Bearing Pendant Propargyl Ethers" (2010). Faculty Publications -- Chemistry Department. 58.

https://digitalcommons.unl.edu/chemfacpub/58

This Article is brought to you for free and open access by the Published Research - Department of Chemistry at DigitalCommons@University of Nebraska - Lincoln. It has been accepted for inclusion in Faculty Publications -Chemistry Department by an authorized administrator of DigitalCommons@University of Nebraska - Lincoln. 


\section{Authors}

Ke Zhang, Joshua I. Cutler, Jian Zhang, Dan Zheng, Evelyn Auyeung, and Chad A. Mirkin 


\title{
Nanopod Formation through Gold Nanoparticle Templated and Catalyzed Cross-linking of Polymers Bearing Pendant Propargyl Ethers
}

\author{
Ke Zhang, Joshua I. Cutler, Jian Zhang, Dan Zheng, Evelyn Auyeung, and Chad A. Mirkin
}

\author{
Department of Chemistry and International Institute for Nanotechnology, \\ Northwestern University, 2145 Sheridan Road, Evanston, Illinois 60208-3113 \\ K. Zhang and J. I. Cutler contributed equally, and should be considered co-first authors. \\ Corresponding author - C. A. Mirkin, chadnano@northwestern.edu
}

\begin{abstract}
A novel method for synthesizing polymer nanopods from a linear polymer bearing pendant propargyl ether groups, using gold nanoparticles as both the template and the catalyst for the crosslinking reaction, is reported. The transformations involved in the cross-linking process are unprecedented on the surface of a gold particle. A tentative cross-linking mechanism is proposed.
\end{abstract}

Hollow nanostructures have attracted significant interest in recent years due to their unique chemical, physical, and biological properties, which suggest a wide range of applications in drug/gene delivery, ${ }^{1-3}$ imaging, ${ }^{4,5}$ and catalysis. ${ }^{6}$ Accordingly, a variety of methods have been developed to synthesize these structures based upon emulsion polymerization, ${ }^{7-9}$ layer-by-layer processes, ${ }_{10}^{10}$ cross-linking of micelles, ${ }^{11-13}$ molecular or nanoparticle self-assembly, 14,15 and sacrificial template techniques. ${ }^{16-19}$ Among them, the templating method is particularly powerful in that it transfers the ability to control the size and shape of the template to the product, for which desired homogeneity and morphology can be otherwise difficult to achieve. In a typical templated synthesis, a sacrificial core is chosen, upon which preferred materials containing latent cross-linking moieties are coated. Following the stabilization of the coating through chemical cross-linking, the template is removed, leaving the desired hollow nanoparticle. This additional cross-linking step can be easily achieved for compositionally simple molecules, such as poly(acrylic acid) or chitosan. ${ }^{20,}{ }^{21}$ However, for systems containing sensitive and/or biologically functional structures, conventional cross-linking chemistries may not be sufficiently orthogonal to prevent the loss of their activity.

In this report, we disclose a method for synthesizing polymer nanopods from a linear polymer bearing pendant propargyl ether groups (1), utilizing gold nanoparticles (AuNPs) as both the template for the formation of the shell and the catalyst for the cross-linking reaction (Scheme 1). No additional cross-linking reagents or synthetic operations are required. This novel reaction is both fundamentally interesting and technologically useful. Indeed, it appears to be the first example of AuNP-catalyzed cross-linking of alkyne-based adsorbates and yields well-defined, homogeneous hollow nanostructures.

$\mathrm{Au}(\mathrm{I})$ and $\mathrm{Au}(\mathrm{III})$ ions and their complexes display remarkable alkynophilicity and have been increasingly recognized as potent catalysts for organic transformations. ${ }^{22-25}$ Recently, it has been demonstrated that $\mathrm{Au}(0)$ surfaces also adsorb terminal alkyne groups and form relatively densely packed and stable monolayers. ${ }^{26}$ However, the type of interaction that exists between the alkyne and the gold surface is not well understood. Moreover, it is not clear whether such interaction makes the alkyne group more susceptible to chemical reactions,
Scheme I. Synthesis of Polyvalent Propargyl Ether Nanopods

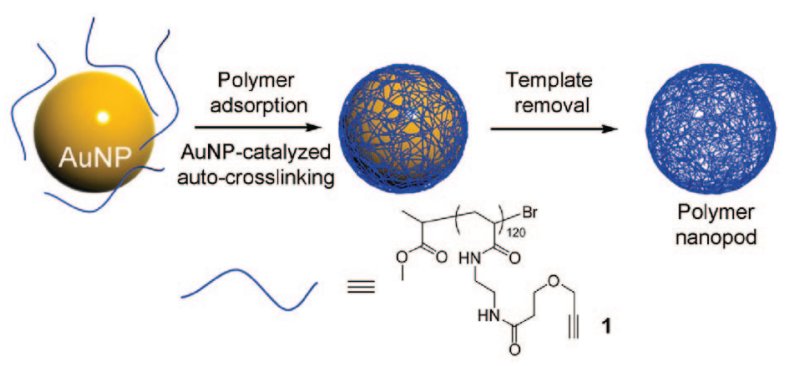

such as nucleophilic additions typically observed with ionic gold-alkyne complexes. Bearing multiple side arm propargyl ether groups, polymer 1 readily adsorbs onto citrate-stabilized $13 \mathrm{~nm}$ AuNPs prepared in an aqueous solution following the Turkevich-Frens method. ${ }^{27}, 28$ X-ray photoelectron spectroscopy (XPS) confirmed the adsorption of the polymer onto AuNPs (Figure S1-A). Excess polymer was removed by iterative centrifugation and subsequent resuspension steps. The resulting polymer-coated AuNPs exhibit a plasmon resonance at $524 \mathrm{~nm}$, characteristic of dispersed particles, and there is no evidence of aggregation even after 8 weeks of storage at room temperature. Therefore, even though $\mathbf{1}$ is a potential interparticle cross-linking agent, it does not lead to aggregation of the AuNPs, a conclusion that is corroborated by Dynamic Light Scattering (DLS, Figure S2) and electron microscopy (vide infra).

To determine the surface polymer density, we designed a fluorescence-based titration assay utilizing Alexa Fluor (AF) 488-labeled polymer 1, prepared via click chemistry. Because AuNPs can serve as fluorescence quenchers, when increasing amounts of polymer are added, fluorescence intensities increase at a slower rate while the AuNP surface is being initially covered, and then at a much higher rate thereafter. The onset of the second stage indicates the point at which full coverage has occurred (Figure S3). For $13 \mathrm{~nm}$ AuNPs, it is determined that on average 26.0 polymer chains can adsorb onto each particle, which gives a surface density of $2.27 \mathrm{mg} \mathrm{m}^{-2}$. For $30 \mathrm{~nm}$ AuNPs, 128.3 polymer chains can adsorb onto each particle. The polymer surface density, however, is nearly identical to that determined for the $13 \mathrm{~nm}$ AuNPs $\left(2.32 \mathrm{mg} \mathrm{m}^{-2}\right)$.

Dissolution of the AuNP core was achieved using potassium cyanide $(\mathrm{KCN})$ in the presence of oxygen. When $\mathrm{KCN}$ is added to unmodified citrate-capped AuNPs, the color of the solution instantly changes from red to purple, a consequence of colloid destabilization and particle aggregation. ${ }^{29}$ However, for the polymer-coated AuNPs, the color remains red throughout the dissolution process, only decreasing in intensity until the solution is colorless (Figure 1A). Time dependent UVvis spectra show a gradual blue shift of the plasmon resonance 


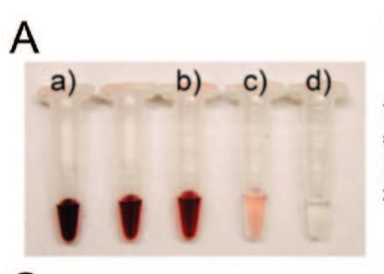

\section{B}

C
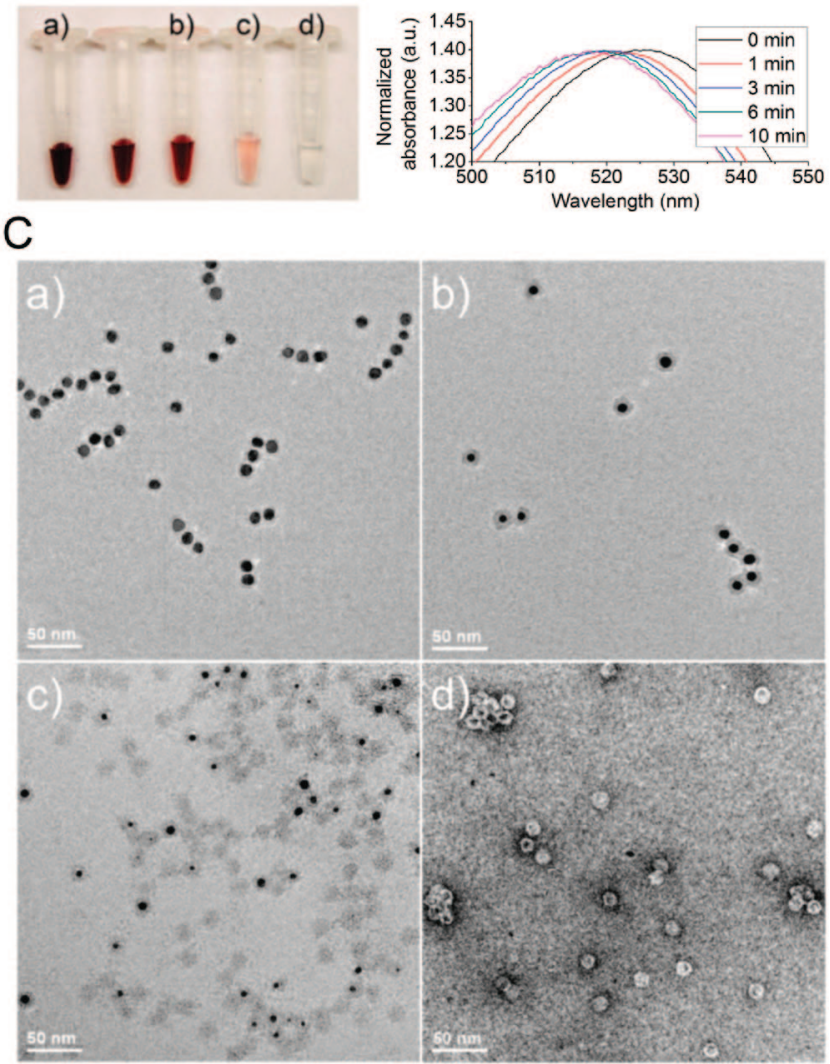

Figure 1. (A) Dissolution process of polymer-coated $13 \mathrm{~nm}$ AuNPs. (B) Normalized UV-vis spectra of AuNPs at various time points during the dissolution process. (C) TEM images of (a) polymer-coated AuNPs, $(\mathrm{b}-\mathrm{c})$ partially formed nanopods, and (d) fully formed nanopods (negatively stained with $0.5 \%$ uranyl acetate).

maximum from 524 to $515 \mathrm{~nm}$ (Figure 1B), as expected from the decrease in AuNP size. ${ }^{30}$ The dissolution process also can be visualized by Transmission Electron Microscopy (TEM) (Figure 1C). As the outer layer of the AuNP was oxidatively dissolved, a gray, uranyl acetate-stained shell could be observed. Complete removal of the template affords nanopods that retain the size of their template with high fidelity. When AuNPs of increasing size were used (13, 20, 30, and $40 \mathrm{~nm}$ ), the resulting nanopods reflected the size of the NP templates, as determined by DLS and TEM (Figure 2).

These observations lead us to conclude that $\mathbf{1}$ has formed a cross-linked shell around the AuNPs, thereby preventing the partially dissolved AuNPs from escaping and aggregating. In this process, the AuNP not only templates the formation of the shell but also catalyzes the cross-linking reaction. This convenient synthesis of nanopods could in principle open up a new avenue to a broad range of functional nanostructures.

However, the microscopy experiments do not provide an understanding of the chemistry that underlies the formation of the nanopods. To probe this issue more deeply, we followed the reaction on the particle surface by IR and NMR spectroscopy and with model ligands and complexes. IR spectroscopy of 1 before and after cross-linking on the surface of the $13 \mathrm{~nm}$ AuNP shows the complete loss of alkyne $\mathrm{C} \equiv \mathrm{C}$ stretching (2114 $\left.\mathrm{cm}^{-1}\right), \mathrm{C}-\mathrm{H}$ stretching $\left(3805 \mathrm{~cm}^{-1}\right)$, and $\mathrm{C}-\mathrm{H}$ bending (1274, $646 \mathrm{~cm}^{-1}$ ) modes, indicating that the propargyl ether group is directly involved in the reaction (Figure S4-D). NMR spectroscopy of the nanopods made from $13 \mathrm{~nm}$ AuNPs proved difficult due to low sensitivity, line broadening, and extensive signal overlap. However, $5 \mathrm{~nm}$ AuNPs yield nanopods

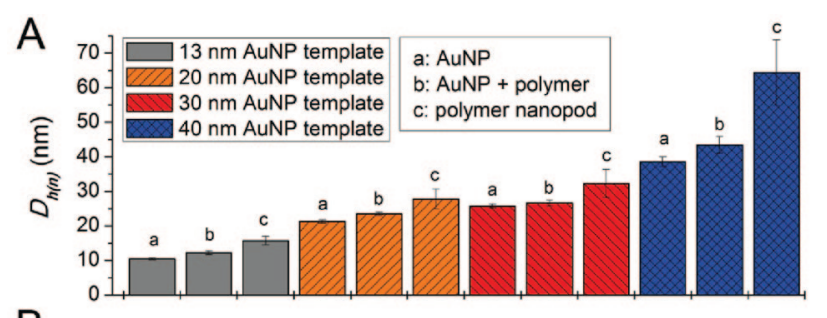

B

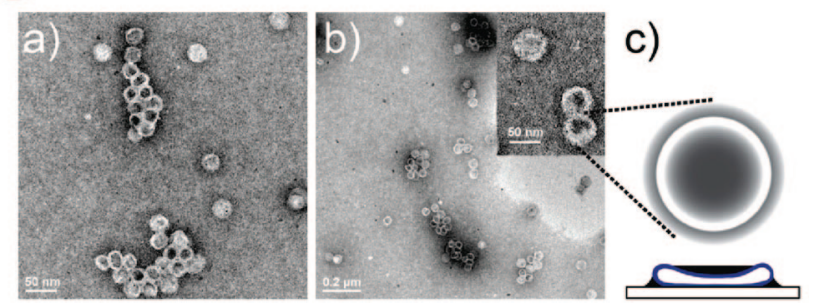

Figure 2. (A) Number-average hydrodynamic diameters of AuNPs $(13,20,30$, and $40 \mathrm{~nm})$, polymer-coated AuNPs, and polymer nanopods. (B) TEM images of (a) $20 \mathrm{~nm}$ nanopods and (b) $40 \mathrm{~nm}$ nanopods (negatively stained with $0.5 \%$ uranyl acetate). In (c) it is illustrated why nanopods appear as donut-shaped in TEM. Black: uranyl acetate stain. Blue: deflated nanopod on a surface.

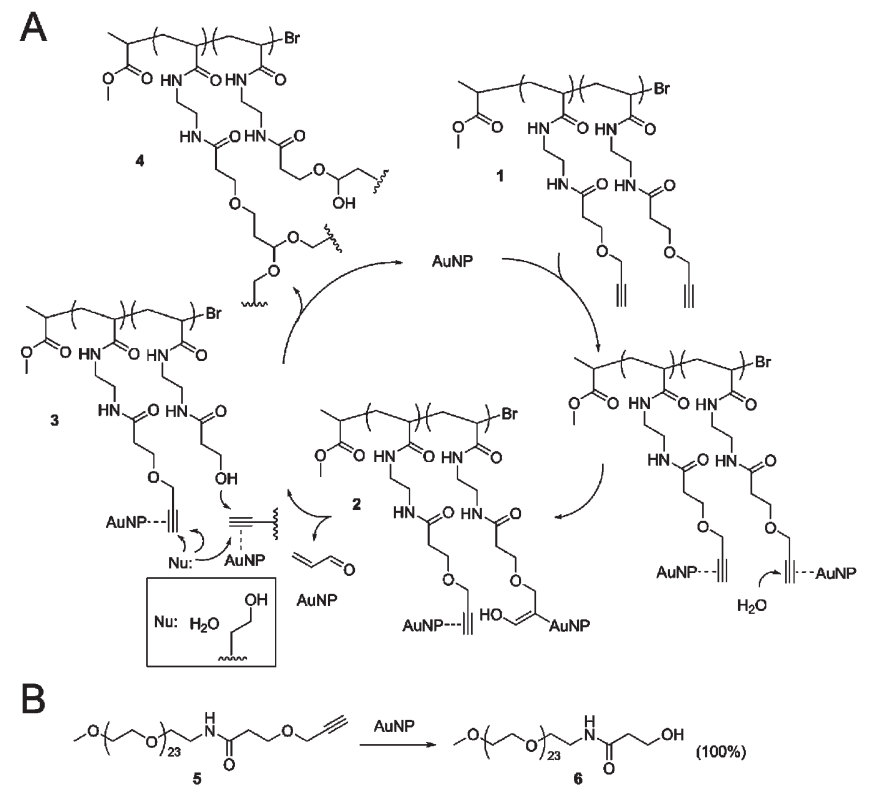

Figure 3. (A) Tentative cross-linking mechanism. (B) A poly(ethylene glycol) 24 -propargyl ether conjugate model system.

sufficiently small to be analyzed. ${ }^{1} \mathrm{H}$ and ${ }^{13} \mathrm{C}$ NMR spectroscopy showed the loss of resonances from the propargyl group, which likely occurs via elimination of acrylaldehyde to form a hydroxyl group. ${ }^{31}$ The resulting hydroxyl group then serves as a new nucleophile for remaining alkyne-Au complexes to generate acetal linkages. ${ }^{32}$ Indeed, the ${ }^{1} \mathrm{H}-{ }^{13} \mathrm{C}$ HSQC spectrum shows the appearance of resonances indicative of the $\mathrm{a}-\mathrm{H}$ of a primary alcohol $\left(\delta 3.81 \mathrm{ppm},{ }^{1} \mathrm{H}\right)$, an alkyl ether $(\delta 3.74 \mathrm{ppm}$, $\left.{ }^{1} \mathrm{H}\right)$, and an acetal $\left(\delta 4.32 \mathrm{ppm},{ }^{1} \mathrm{H}\right)$ group (Figure S4-B and S4C). Moreover, the $\mathrm{C} 1 \mathrm{~s}$ peak in the XPS of the polymer-gold complex exhibits a shoulder at $291.3 \mathrm{eV}$, consistent with the presence of an acetal carbon and our proposed mechanism (Figure S1-B). Such transformations are previously known to be possible only with ionic gold catalysts. Although a detailed mechanism of the present protocol awaits further studies, a plausible pathway can be advanced (Figure 3A). Coordination of the alkynophilic AuNP to $\mathbf{1}$ is followed by the nucleophilic 
addition of water to yield intermediate 2, which forms 3 by elimination. Because of high local concentrations on the surface of the AuNP, reaction between the hydroxyl groups and $\mathrm{Au}$-alkyne complexes is possible without high temperatures, giving acetal and ether cross-links 4 and regenerating the catalyst AuNP. However, the AuNP cannot catalyze further reactions because the dense shell that forms prevents it from accessing free polymers. Indeed, we found that the free polymers separated from the reaction mixtures were exclusively the starting material 1.

To gain further insight into the proposed mechanism, we synthesized a monodisperse poly(ethylene glycol) ${ }_{24}$-propargyl ether conjugate 5, which allowed for convenient mass and NMR analyses (Figure 3B). Because 5 contains only one propargyl ether moiety, once it loses the gold-binding alkyne group, it can no longer bind to the AuNP surface, thereby exposing the AuNP surface to catalyze further reactions. Indeed, upon incubation with AuNPs and subsequent removal of AuNPs through centrifugation, 5 was converted to the primary alcohol 6 quantitatively as evidenced by matrix-assisted laser desorption/ionization time-of-flight mass spectrometry (MALDI-ToF MS) and NMR spectroscopy (Figure S5). This is in contrast to the polymer system, wherein only the polymers associated with the AuNPs were subject to catalysis due to the irreversible formation of a dense shell. These results are consistent with the conclusion that the AuNP is the catalyst for the chemical transformations (vide supra).

In summary, we have demonstrated a novel method for synthesizing well-defined polymer nanopods from a linear polymer with pendant propargyl ether groups, using a AuNP as the template and the catalyst for the cross-linking reaction. The size of the nanopods can be controlled by choosing different AuNP templates. We envisage that this general strategy can be applied to create a variety of complex and functional systems that are applicable in a broad range of disciplines.

Acknowledgments - We thank the NCI-CCNE program, the DOE Office (Award No. DE-SC0000989) for support via the NU Non-equilibrium Energy Research Center, and the NSFNSEC program for financial support. Electron microscopy was performed in the EPIC facility of the NUANCE center at Northwestern University.

Supporting Information - Experimental procedures and characterization data follow the References.

\section{References}

1. Shu, S., Zhang, X., Wu, Z., Wang, Z., and Li, C. Biomaterials 2010, 31, 6039

2. Kim, E., Kim, D., Jung, H., Lee, J., Paul, S., Selvapalam, N., Yang, Y., Lim, N., Park, C. G., and Kim, K. Angew. Chem., Int. Ed. 2010, 49, 4405

3. Kasuya, T., Jung, J., Kinoshita, R., Goh, Y., Matsuzaki, T., Iijima, M., Yoshimoto, N., Tanizawa, K., and Kuroda, S. i. In Methods in Enzymology; Nejat, D., Ed.; Academic Press: 2009; Vol. 464, p 147.
4. Sharma, S., Paiphansiri, U., Hombach, V., Mailänder, V., Zimmermann, O., Landfester, K., and Rasche, V. Contrast Media Mol. Imaging 2010, 5, 59

5. Tan, H., Liu, N. S., He, B., Wong, S. Y., Chen, Z.-K., Li, X., and Wang, J. Chem. Commun. 2009, 6240

6. Choi, S.-H., Gopalan, A. I., Ryu, J.-H., and Lee, K.-P. Mater. Chem. Phys. 2010, 120, 18

7. Anton, N., Benoit, J.-P., and Saulnier, P. J. Controlled Release 2008, 128, 185

8. Landfester, K., Musyanovych, A., and Mailänder, V. J. Polym. Sci., Part A: Polym. Chem. 2010, 48, 493

9. Li, W., Yoon, J. A., and Matyjaszewski, K. J. Am. Chem. Soc. 2010, 132, 7823

10. Kondo, K., Kida, T., Ogawa, Y., Arikawa, Y., and Akashi, M. J. Am. Chem. Soc. 2010, 132, 8236

11. Turner, J. L. and Wooley, K. L. Nano Lett. 2004, 4, 683

12. Sugihara, S., Armes, S. P., and Lewis, A. L. Angew. Chem., Int. Ed. 2010, 49, 3500

13. Moughton, A. O., Stubenrauch, K., and O'Reilly, R. K. Soft Matter 2009, 5, 2361

14. Kim, D., Kim, E., Kim, J., Park, K. M., Baek, K., Jung, M., Ko, Y. H., Sung, W., Kim, H. S., Suh, J. H., Park, C. G., Na, O. S., Lee, D.-k., Lee, K. E., Han, S. S., and Kim, K. Angew. Chem., Int. Ed. 2007, 46, 3471

15. Kim, D., Kim, E., Lee, J., Hong, S., Sung, W., Lim, N., Park, C. G., and Kim, K. J. Am. Chem. Soc. 2010, 132, 9908

16. Réthoré, G. and Pandit, A. Small 2010, 6, 488

17. Marinakos, S. M., Novak, J. P., Brousseau, L. C., House, A. B., Edeki, E. M., Feldhaus, J. C., and Feldheim, D. L. J. Am. Chem. Soc. $1999,121,8518$

18. Caruso, F., Caruso, R. A., and Möhwald, H. Science 1998, 282, 1111

19. Liz-Marzán, L. M., Giersig, M., and Mulvaney, P. Langmuir 1996, 12, 4329

20. Cheng, C., Qi, K., Khoshdel, E., and Wooley, K. L. J. Am. Chem. Soc. 2006, 128, 6808

21. Hu, Y., Ding, Y., Ding, D., Sun, M., Zhang, L., Jiang, X., and Yang, C. Biomacromolecules 2007, 8, 1069

22. Hashmi, A. S. K. Chem. Rev. 2007, 107, 3180

23. Li, Z., Brouwer, C., and He, C. Chem. Rev. 2008, 108, 3239

24. Fürstner, A. and Davies, P. W. Angew. Chem., Int. Ed. 2007, 46,3410

25. Hashmi, A. S. K. and Hutchings, G. J. Angew. Chem., Int. Ed. 2006, 45, 7896

26. Zhang, S., Chandra, K. L., and Gorman, C. B. J. Am. Chem. Soc. 2006, 129, 4876

27. Frens, G. Colloid Polym. Sci. 1972, 250, 736

28. Turkevich, J., Stevenson, P. C., and Hillier, J. Discuss. Faraday Soc. 1951, 11, 55

29. Daniel, M.-C. and Astruc, D. Chem. Rev. 2003, 104, 293

30. Link, S. and El-Sayed, M. A. J. Phys. Chem. B 1999, 103, 4212

31. Fukuda, Y. and Utimoto, K. Bull. Chem. Soc. Jpn. 1991, 64, 2013

32. Fukuda, Y. and Utimoto, K. J. Org. Chem. 1991, 56, 3729 


\title{
Supporting Information for
}

\author{
Nanopod Formation Through Gold Nanoparticle Templated and \\ Catalyzed Crosslinking of Polymers Bearing Pendant Propargyl Ethers \\ Ke Zhang ${ }^{\dagger}$, Joshua I. Cutler ${ }^{\dagger}$, Jian Zhang, Dan Zheng, Evelyn Auyeung and Chad A. Mirkin* \\ Department of Chemistry and International Institute for Nanotechnology, Northwestern University, \\ 2145 Sheridan Rd, Evanston, Illinois, 60208-3113 \\ ${ }^{\dagger}$ These authors contributed equally

\section{Experimental details}

All materials were purchased from Sigma-Aldrich Co., MO, USA, and used without further purification unless otherwise indicated. TEM characterization was conducted on a Hitachi H8100 electron microscope (Hitachi High-Tech Co., Japan). NMR experiments were performed using a Bruker Avance III $500 \mathrm{MHz}$ coupled with a DCH CryoProbe (Bruker BioSpin Co., MA, USA). DLS data were acquired from a MALVERN Zetasizer, Nano-ZS (Malvern Instruments, UK). IR results were obtained from a Bruker TENSOR 37, and analyzed using the OPUS software (Bruker Optics Inc., MA, USA). MALDI-ToF measurements were carried out on a Bruker Autoflex III SmartBeam mass spectrometer (Burker Daltonics Inc., MA, USA). Tetrahydrofuran-based gel permeation chromatography (THF GPC) was conducted on a Waters Chromatography, Inc. (MA, USA) model 1515 GPC, equipped with a Waters model 5414 differential refractometer, a Precision Detectors, Inc. (MA, USA) model PD-2026 dual-angle $\left(15^{\circ}\right.$ and $\left.90^{\circ}\right)$ light scattering detector, and Polymer Laboratories, Inc. (MA, USA) gel mixed-bed styrene-divinylbenzene columns (PLgel $5 \mu \mathrm{m}$ Mixed C, $500 \AA$, and $104 \AA$, 300 x $7.5 \mathrm{~mm}$ columns). Fluorescence measurements were carried out with a Fluorolog-3 system (HORIBA Jobin Yvon Inc., NJ, USA). UV-Vis data were obtained on a Cary 5000 UV-Vis spectrophotometer (Varian Inc., CA, USA). XPS spectra were taken using an Omicron ESCA Probe X-ray photoelectron spectrometer (Omicron NanoTechnology GmbH, Germany).

\section{Synthesis of poly( $N$-(2-(3-(prop-2-ynyloxy)propanamido)ethyl)acrylamide) $\mathbf{1}$ :}

Polyacrylamidoethylamine $_{120}\left(\mathrm{PAEA}_{120}\right)$ was prepared following literature reported methods with minor modifications. $^{1,2}$ Briefly, poly(acrylic acid) ${ }_{120}$ (synthesized via atom transfer radical polymerization of tbutyl acrylate followed by deprotection with trimethyl iodide) is activated by O-benzotriazole- $N, N, N^{\prime}, N^{\prime}$ tetramethyl-uronium-hexafluoro-phosphate /hydroxybenzotriazole in DMF, followed by amidation using $N$-Boc ethylene diamine to afford PAEA-Boc 120 . THF GPC of PAEA-Boc ${ }_{120}$ indicates a narrow molecular weight distribution ( $\mathrm{PDI}=1.18)$. Excess aqueous $\mathrm{HCl}(2.0 \mathrm{M})$ was used to remove the Boc protecting group ( $4 \mathrm{~h}$ in RT), giving $\mathrm{PAEA}_{120}$. $\mathrm{PAEA}_{120}(67.5 \mathrm{mg}, 4.9 \mu \mathrm{mol})$ was dissolved in anhydrous DMSO (2 $\mathrm{mL}$ ), and stirred for $3 \mathrm{~h}$, before $1 \mathrm{~mL}$ of a DMSO solution containing propargyl-dPEG ${ }_{1}-\mathrm{NHS}$ ester (150 mg, $660 \mu \mathrm{mol}$, Quanta Biodesign Ltd., OH, USA) and diisopropylethylamine (DIPEA, $204 \mu \mathrm{L} 1.17 \mathrm{mmol}$ ) was added. The reaction mixture was allowed to stir overnight, diluted by the addition of DMSO $(10 \mathrm{~mL})$, transferred to pre-soaked dialysis tubing $(\mathrm{MWCO}=3.5 \mathrm{kDa})$, and dialyzed against Nanopure $^{\mathrm{TM}}$ water $(>18.0 \mathrm{M} \Omega \bullet \mathrm{cm})$ for 3 days. The solution was then lyophilized and re-suspended in water $(15 \mathrm{~mL})$. A small amount of cloudiness was observed, which was removed by filtering through a $0.2 \mu \mathrm{m}$ syringe filter. No residual amine groups were detected by a ninhydrin test. The polymer exhibits a lowest critical solution temperature (LCST) of $28.8^{\circ} \mathrm{C}$ as determined by light scattering while monitoring by UV-Vis spectroscopy at $600 \mathrm{~nm}$. The solubility of the polymer increased with decreasing temperature (room temp- $0{ }^{\circ} \mathrm{C}$ ). Calculated molecular weight: $27.0 \mathrm{kDa} .{ }^{1} \mathrm{H}^{13} \mathrm{C}$ HSQC NMR and IR spectra of $\mathbf{1}$ are shown in Fig. S1-A and S1-D, respectively.

2. Synthesis of methyl-terminated poly(ethylene glycol)-propargyl ether conjugate 5: 
Monodisperse $\mathrm{mPEG}_{24}$-amine (39.0 mg, $34.6 \mu \mathrm{mol}$, Quanta Biodesign) was dissolved in $1.0 \mathrm{~mL} \mathrm{pH}=8.0$ phosphate buffer, to which propargyl- $\mathrm{dPEG}_{1}-\mathrm{NHS}$ ester $(12.1 \mathrm{mg}, 53.7 \mu \mathrm{mol})$ was added. The mixture was allowed to be shaken for 12 hours at $4{ }^{\circ} \mathrm{C}$. The desired conjugate was isolated from the reaction mixture by reverse phase HPLC (water/acetonitrile, Varian DYNAMAX C18 column $(250 \times 10.0 \mathrm{~mm}))$. MALDI-ToF: $1220.553[\mathrm{M}+\mathrm{Na}]^{+} .{ }^{1} \mathrm{H}^{-13} \mathrm{C}$ HSQC: Fig. S2.

3. Synthesis of $13 \mathrm{~nm}$ AuNPs.

An aqueous solution of $\mathrm{HAuCl}_{4}(1 \mathrm{mM}, 500 \mathrm{~mL})$ was brought to reflux while stirring, and then trisodium citrate solution $(50 \mathrm{~mL}, 77.6 \mathrm{mM})$ was added quickly to the boiling mixture. The solution was refluxed for an additional $15 \mathrm{~min}$, and allowed to cool to room temperature. The average diameter of the gold nanoparticles was determined by TEM $(12.8 \pm 1.2 \mathrm{~nm})$. AuNPs of other sizes used in this study were purchased from Ted Pella Inc., CA, USA.

4. General method for the preparation of nanopods.

To $10 \mathrm{~mL}$ AuNP solution (10 nM), $10 \mu \mathrm{L}$ of $10 \%$ sodium dodecyl sulfate solution was added. Then, an aqueous solution containing 1 was added to give a final concentration of $20 \mathrm{nM}$. The solution was stirred for 2 days, before being subjected to centrifugation using an Eppendorf 5424 centrifuge at 15,000 rpm for 30 min. Supernatant was removed by careful pipetting, and the AuNP was resuspended in Nanopure ${ }^{\mathrm{TM}}$ water. The process was repeated 3 times to ensure complete removal of excess polymers. After the final centrifugation, the polymer-coated AuNP were concentrated to $1 \mathrm{~mL}$, and $50 \mu \mathrm{L}$ of $1.0 \mathrm{M}$ $\mathrm{KCN}$ aqueous solution was added to remove the gold core. The resulting solution was then dialyzed against Nanopure ${ }^{\mathrm{TM}}$ water $(>18.0 \mathrm{M} \Omega \bullet \mathrm{cm}$ ) using pre-soaked dialysis tubing (MWCO $=6-8 \mathrm{kDa}$ ) for 3 days. The final nanopod solution appeared clear and slightly yellow. A large volume of gold nanoparticle templates $(>500 \mathrm{~mL})$ was required to prepare sufficient quantity of nanopods for NMR and IR analyses. The concentration of citrate capped gold nanoparticles prior to the addition of polymer $\mathbf{1}$ must not exceed $0.5 \mu \mathrm{M}$ (optimal 10-100 $\mathrm{nM}$ ) in order for the resulting nanopods to be aggregate-free.

5. $\quad$ Functionalization of polymer $\mathbf{1}$ with Alexa Fluor 488.

To $3.0 \mathrm{~mL}$ of a $3.54 \mathrm{mg} / \mathrm{mL}$ aqueous polymer 1, $0.50 \mathrm{mg}$ Alexa Fluor 488-azide (Invitrogen, OR, USA) was added as a $1.5 \mathrm{~mL}$ aqueous solution. Sodium ascorbate $(4.5 \mathrm{mg})$ was dissolved in this mixture to give a concentration of $5.0 \mathrm{mM}$. Tris-(hydroxypropyltriazolylmethyl)amine (synthesized following literature reported method) ${ }^{3}$ and $\mathrm{CuSO}_{4}$ were mixed in 5:1 molar ratio in water, and added to the polymer mixture to give a final copper ion concentration of $0.1 \mathrm{mM}$. The solution was stirred at room temperature $\left(21{ }^{\circ} \mathrm{C}\right)$ overnight. After the reaction, the mixture was dialyzed against Nanopure ${ }^{\mathrm{TM}}$ water $(>18.0 \mathrm{M} \Omega \bullet \mathrm{cm})$ using pre-soaked dialysis tubing ( $\mathrm{MWCO}=3.5 \mathrm{kDa}$ ) for 3 days to remove copper ions and unreacted Alexa Fluor 488-azide. The purified polymer was lyophilized and resuspended in water to give a final concentration of $2.37 \mathrm{mg} / \mathrm{mL}$.

6. General procedure for the quantification of AuNP surface-bound polymers.

AuNPs $(10.0 \mathrm{nM})$ were separated into $16 \times 1.0 \mathrm{~mL}$ aliquots, which were each concentrated by centrifugation to a final volume of $100 \mu \mathrm{L}(100 \mathrm{nM})$. To each of the concentrated solutions, $0.2-20.0 \mu \mathrm{L}$ of the AF488labeled polymer 1 solution $(87.4 \mu \mathrm{M})$ were added. The mixtures were allowed to react overnight. After the reaction, the solutions were diluted to $2.0 \mathrm{~mL}$, and their fluorescence was measured (excitation: $488 \mathrm{~nm}$; emission: $515 \mathrm{~nm}$ ). Fluorescence intensities were plotted against polymer concentration. Fluorescence increased with regard to polymer concentration at a lower rate before the AuNP surface was consumed, and at a higher rate thereafter. Each stage appeared to have a linear relationship. The inflection point, that is, 
when the surface of the AuNP becomes completely covered by polymer chains, can be identified from the plot as the onset of the second stage. The number of polymers per AuNP can be calculated by:

Number of polymers per AuNP $=[\text { polymer }]_{\text {inflection point }} /[$ AuNP $]$
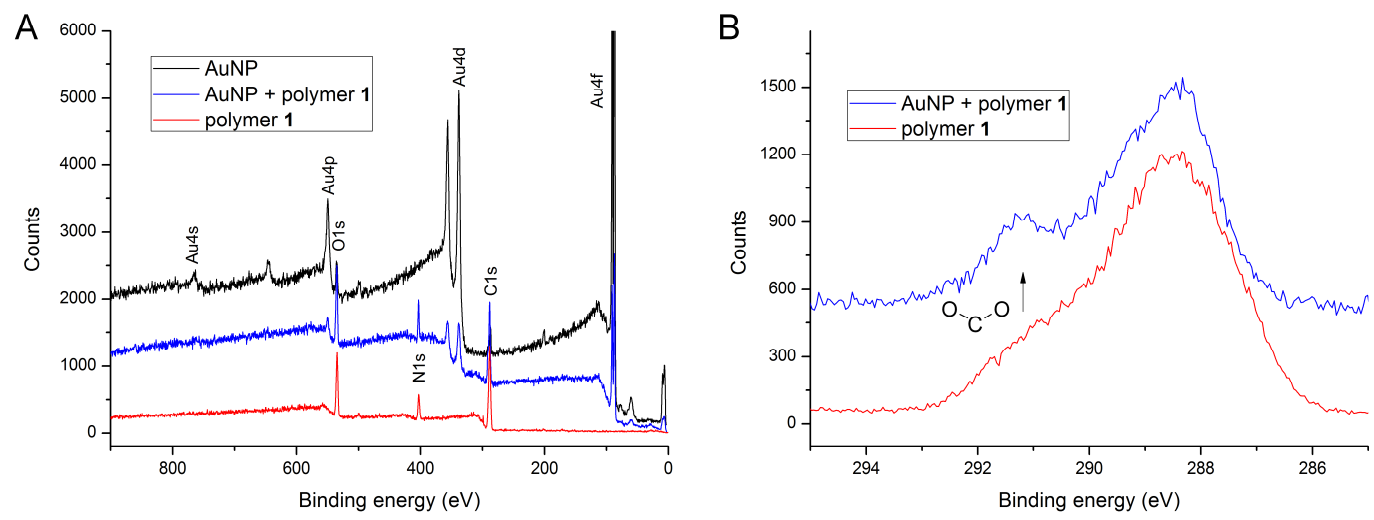

Figure S1. A. XPS survey spectra of AuNPs, AuNP-polymer complexes and polymer $\mathbf{1}$ on silicon wafer. B. Detailed scan of the $\mathrm{C} 1 \mathrm{~s}$ region.
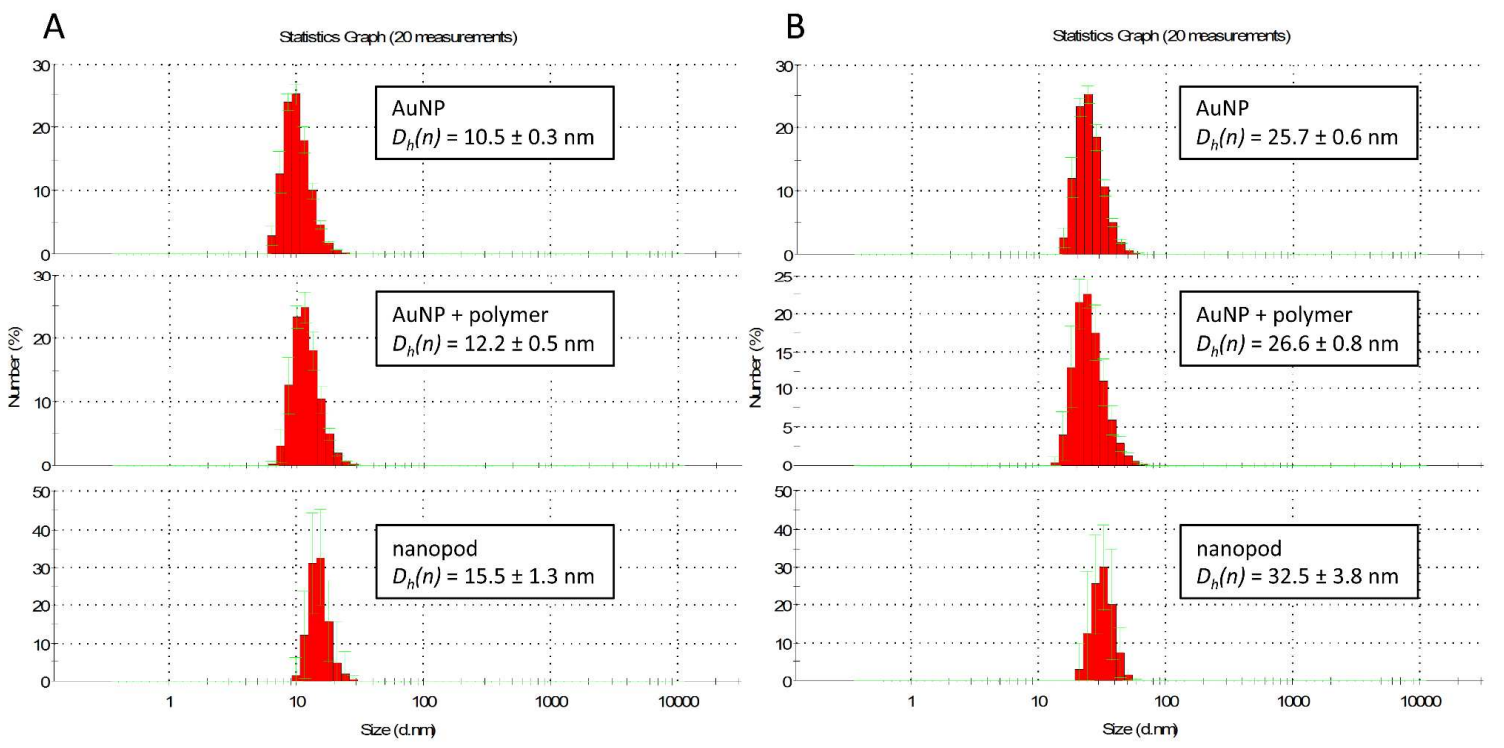

Figure S2. DLS number-average hydrodynamic diameter distribution graphs for AuNPs, AuNP-polymer complexes, and polymer nanopods based on A) $13 \mathrm{~nm}$ and B) $30 \mathrm{~nm}$ AuNP cores. Standard deviation is calculated from 20 independent measurements. The unimodal distributions indicate no aggregation. 

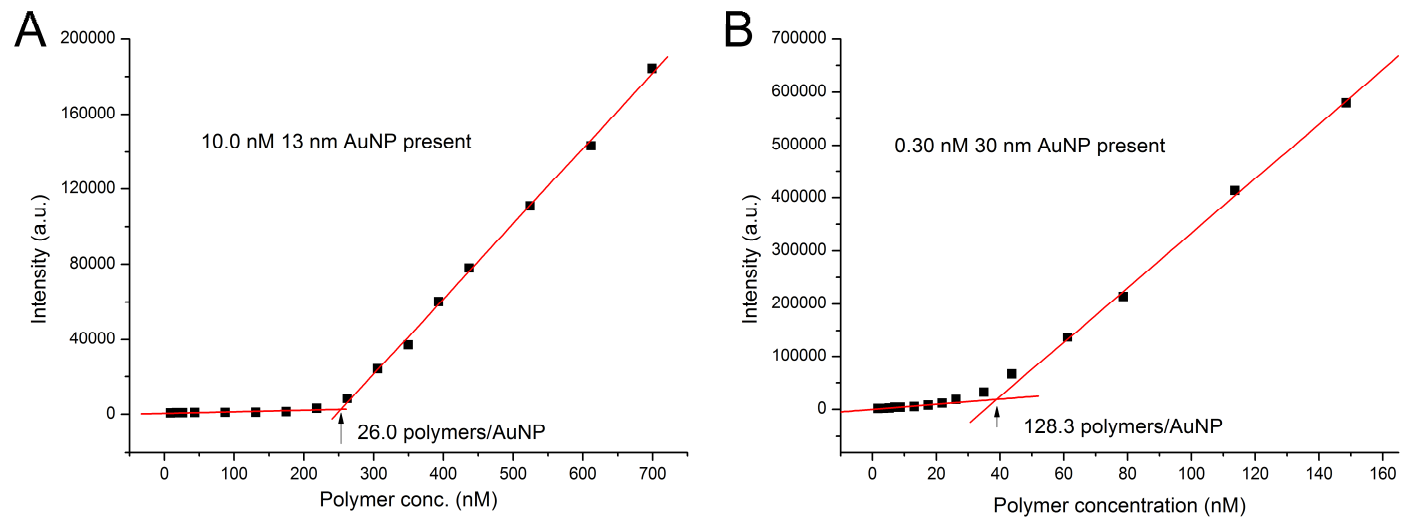

Figure S3. Titration of AuNP surface (A. $13 \mathrm{~nm}$ B. $30 \mathrm{~nm}$ ) with AF488-labeled polymer 1. Fluorescence intensities increase with regard to polymer concentration at a lower rate before the AuNP surface is saturated with polymer chains, and at a higher rate thereafter (two stages). The onset of the second stage

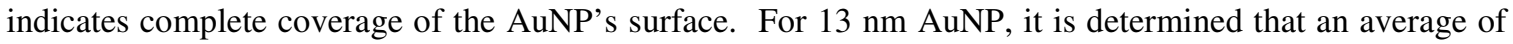
26.0 polymers are required to completely cover the surface of each particle, giving a surface density of 2.27 $\mathrm{mg} / \mathrm{m}^{2}$ (TEM number-averaged diameter of $12.8 \mathrm{~nm}$ used in calculation). For $13 \mathrm{~nm}$ AuNP, 128.3 polymers are required to completely cover the surface of each particle. Polymer surface density is 2.32 $\mathrm{mg} / \mathrm{m}^{2}$ (TEM number-averaged diameter of $28.1 \mathrm{~nm}$ used in calculation). 

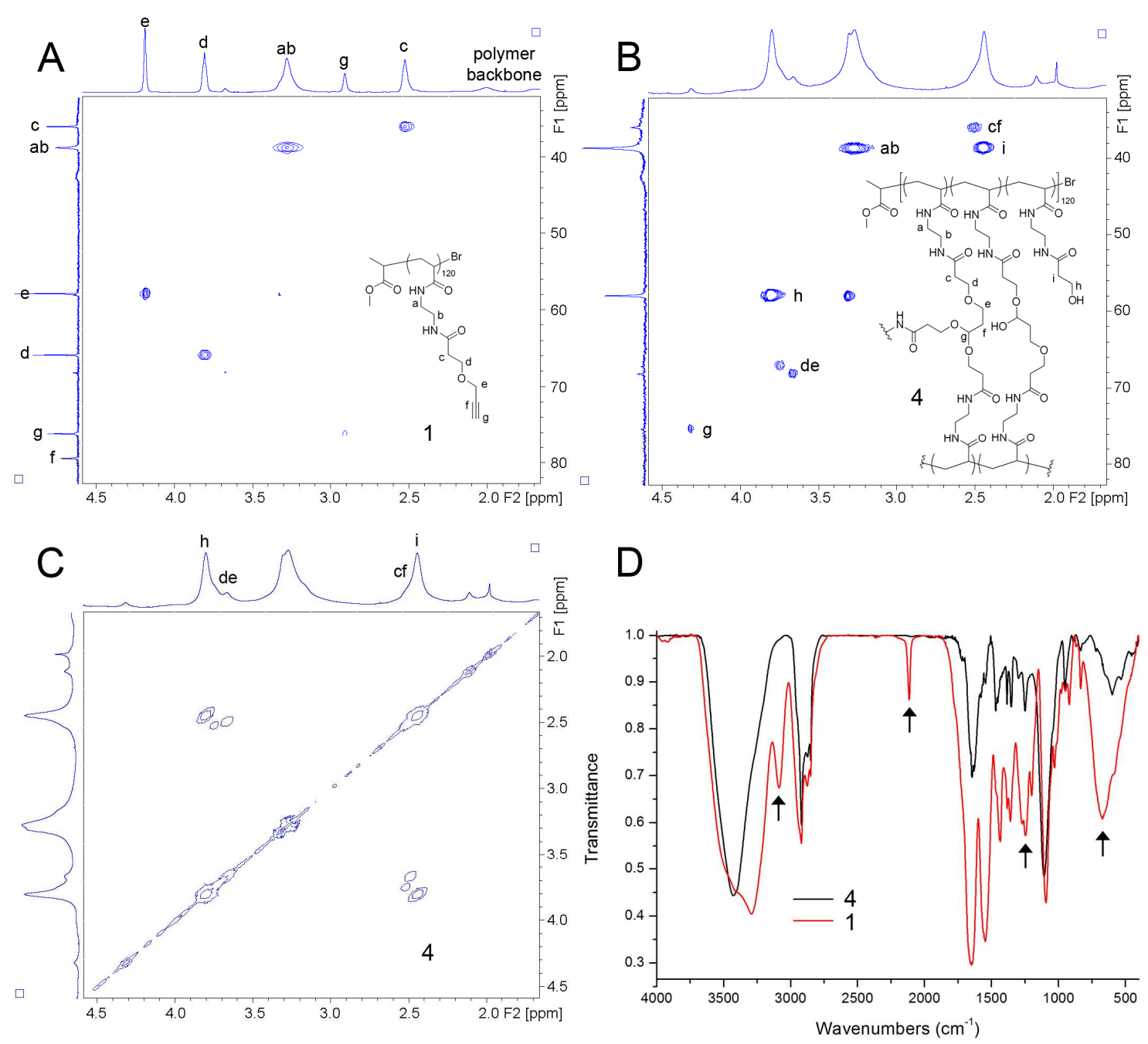

Figure S4. A. ${ }^{1} \mathrm{H}^{13}{ }^{13} \mathrm{C}$ HSQC of $\mathbf{1}$ in $\mathrm{D}_{2} \mathrm{O}$. B. ${ }^{1} \mathrm{H}-{ }^{13} \mathrm{C}$ HSQC of 4 in $\mathrm{D}_{2} \mathrm{O}$. C. ${ }^{1} \mathrm{H}-{ }^{1} \mathrm{H}$ COSY of 4 in $\mathrm{D}_{2} \mathrm{O}$, showing h-i, c-d and e-f correlations. D. IR spectra of $\mathbf{1}$ (red) and $\mathbf{4}$ (black), showing the loss of alkynerelated vibrations, most notably the $\mathrm{C} \equiv \mathrm{C}$ stretching $\left(2114 \mathrm{~cm}^{-1}\right)$. 

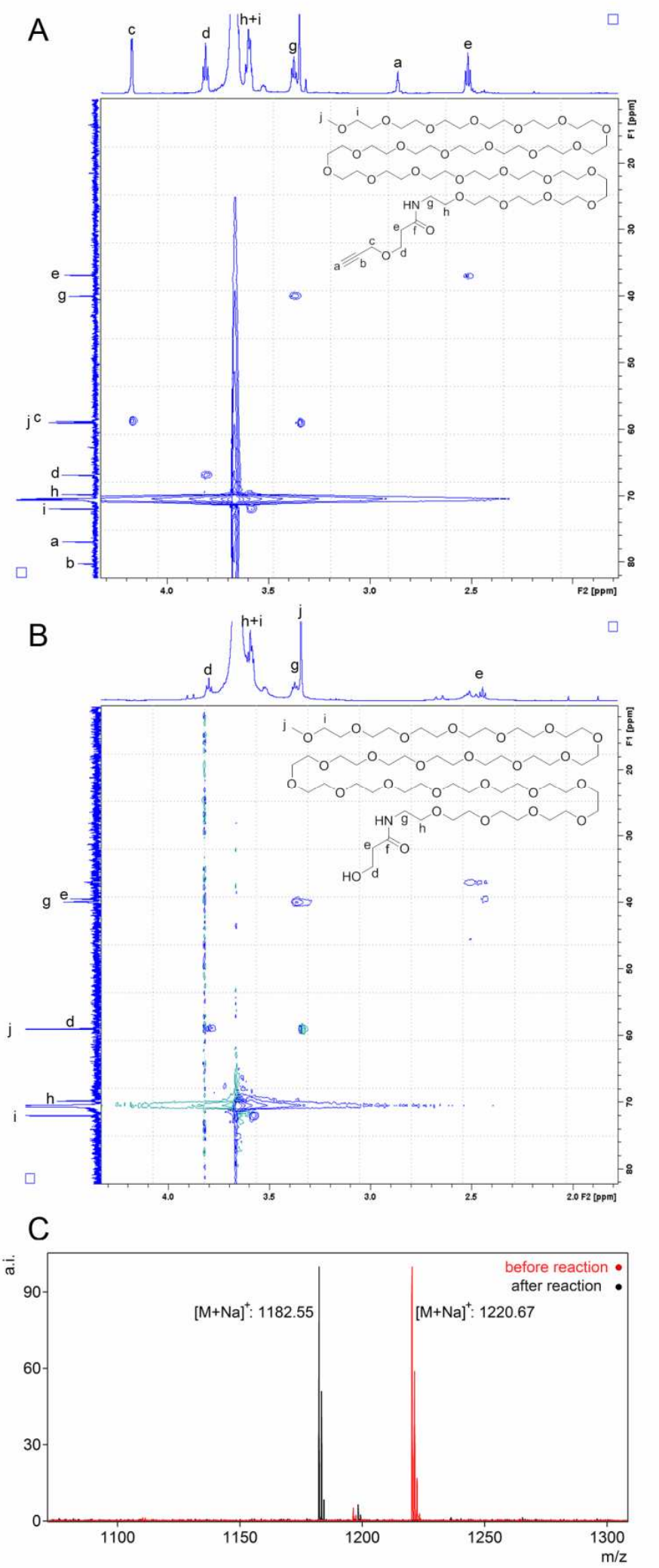

Figure S5. A. ${ }^{1} \mathrm{H}^{-13} \mathrm{C}$ HSQC for 5 in $\mathrm{D}_{2} \mathrm{O}$. B. ${ }^{1} \mathrm{H}^{-}{ }^{13} \mathrm{C}$ HSQC for 5 in $\mathrm{D}_{2} \mathrm{O}$ after reaction. C. MALDI-ToF MS for $\quad \mathbf{5}$ before and after 
(1) Zhang, K.; Fang, H. F.; Wang, Z. H.; Li, Z.; Taylor, J. S. A.; Wooley, K. L. Biomaterials 2010, 31, 1805.

(2) Zhang, K.; Fang, H. F.; Wang, Z. H.; Taylor, J. S. A.; Wooley, K. L. Biomaterials 2009, $30,968$.

(3) Hong, V.; Presolski, S.; Ma, C.; Finn, M. Angew. Chem. Int. Ed. 2009, 48, 9879. 